\title{
Pensamento computacional na educação básica: interface tecnológica na construção de competências do século XXI
}

\author{
Debora Conforto*, Patrícia Cavedini**, Roxane Miranda***, Saulo Caetano ${ }^{\star \star \star \star}$
}

\section{Resumo}

Este artigo discute a implementação da ação pedagógica Oficina de Pensamento Computacional no âmbito da educação básica, em Porto Alegre, objetivando socializar uma das possíveis respostas para o desafio de alinhar a escola às demandas colocadas por um contexto sociocultural, político e econômico edificado pelas tecnologias da informação e comunicação. Problematizam-se as premissas que justificam a inclusão dessa ação na grade curricular, delineando as estratégias de implementação, de acompanhamento e de avaliação, especialmente por escutar os participantes e dar voz a eles.

Palavras-chave: Educação básica. Pensamento computacional. Tecnologia.

\section{Introdução}

A educação não evoluiu para acompanhar as necessidades do mundo contemporâneo, produzido por relações globalizadas e por tecnologias radicalmente transformadoras. A partir dessa constatação, Jim Lengel, em 2013, evidenciou o descompasso de instituições educativas que, ao mesmo tempo em que pregam a inovação, ainda não abandonaram práticas que valorizam a memorização, como o recitar de fatos e de fenômenos em detrimento do desenvolvimento de habilidades necessárias para viver o hoje e o amanhã.

* Doutora em Educação, supervisora de tecnologias educacionais, Rede Marista, Província Brasil Sul Amazônica. E-mail: debora@maristas.org.br

** Mestre em Informática na Educação, professora de tecnologias educacionais do Colégio Marista Rosário, Rede Marista, Província Brasil Sul Amazônica. E-mail: patricia@maristas.org.br

*** Especialista em Informática na Educação, monitora de tecnologias educacionais do Colégio Marista Rosário, Rede Marista, Província Brasil Sul Amazônica. E-mail: roxane@maristas.org.br

**** Especialista em Informática na Educação, instrutor de robótica do Colégio Marista Rosário, Rede Marista, Província Brasil Sul Amazônica. E-mail: saulo.caetano@maristas.org.br 
O avanço no domínio de habilidades permitiu que a humanidade progredisse na resolução de problemas e no desenvolvimento de diferentes áreas do conhecimento. Como analisa Lévy (1993), a evolução histórica da humanidade foi alavancada na medida em que as tecnologias da inteligência estabeleceram as condições de possibilidade para ampliar o pensar coletivo: a oralidade, a escrita e a informática. A informática configura-se como a extensão contemporânea da memória humana, com diferenciais qualitativos edificados sob o potencial das tecnologias anteriores e, por isso, sem abandoná-las.

A evolução de habilidades acompanha a história da humanidade. Na Idade Média, como ilustrado na obra de Humberto Eco, O nome da rosa (1983), ler e escrever eram habilidades de domínio exclusivo da nobreza e, principalmente, do clero. Essas habilidades cognitivas, antes restritas a poucos, hoje são de domínio dos estudantes já nos anos iniciais do ensino fundamental. A afirmação da sociedade industrial foi garantida com a ampliação para um conjunto cada vez maior das possibilidades de apropriação pela população de habilidade, como ler, escrever e operar matematicamente. É preciso compreender que, em cada fase da história da humanidade, o domínio de um conjunto mínimo de habilidades possibilitou a inserção do homem em contextos social e laboral diferenciados.
Habilidades são ferramentas cognitivas que permitem ao homem operar nos diferentes contextos socioculturais. A oralidade forjou o homem como um ser social. A apropriação de habilidades relacionadas ao pensar lógico-matemático foi central na resolução de problemas associados às medições de diferentes grandezas, estabelecendo as condições de possibilidade para operar de forma abstrata e para modelar o mundo moderno. Novas habilidades passam a ser exigidas para viver em um mundo pós-industrial marcado por imaginação, criatividade e inovação.

A complexidade do mundo vem exigindo um conjunto de habilidades diferenciadas. Se a lógica organizacional dos tempos, dos espaços e dos conteúdos que produziu a escola que começou a emergir no século XII foi central na construção da sociedade industrial, contemporaneamente, as demandas socioculturais e econômicas passam a exigir uma reconfiguração das instituições educativas, transformando-as em locais de produção de aprendizagens para responder às demandas da sociedade da informação e do conhecimento. A rigidez dos edifícios escolares deve dar lugar à flexibilidade de um desenho institucional no formato dos laboratórios e dos centros de design, espaços-tempos nos quais se desenrola um processo educativo na "versão Beta", pela imposição de constantes atualização e reinvenção. 
O desafio do processo educativo está em construir respostas às demandas colocadas por um contexto social, econômico e cultural alicerçado pelo poder das tecnologias de informação e de comunicação, por isso não pode ser reduzido ao movimento de atualização da configuração tecnológica na escola, um movimento desenhado quase como “darwinismo computacional”. São fundamentais colocar-se na contramão desse enfoque tecnicista e, assim, romper com o paradigma que posiciona estudantes como consumidores de tecnologias, para estabelecer as condições de possibilidade de torná-los produtores de dispositivos e de saberes tecnológicos. Para que esse deslocamento se efetive, é preciso que a "caixa de ferramenta cognitiva" dos estudantes seja acrescida de uma nova habilidade, a do raciocínio ou do pensamento computacional.

As discussões quanto à importância de trazer para estudantes da educação básica a necessidade de desenvolver uma habilidade de pensamento cada vez mais requisitada na atualidade não partiram das agendas educacionais e, tão pouco, compõem o currículo de cursos para a formação em informática na educação, mas emergiram como objetivo estratégico no âmbito da computação. As críticas aos resultados do ensino de informática nos últimos anos foram produzidas dentro da comunidade das ciências da computação. As pesquisas do Massachusetts
Institute of Technology (MIT), com foco na forma como o computador vem sendo utilizado na escola, ou a implementação de programas como o One Laptop per Child (1:1) ilustram os esforços do mundo acadêmico. Empresas como Google, Microsoft e IBM também têm despendido expressivos investimentos para potencializar a inserção da tecnologia na educação básica. É importante destacar que não há nada de tão altruísta nesses movimentos acadêmicos e empresariais, pois a escassez de profissionais na área da programação e a carência de estudantes nas áreas de desenvolvimento tecnológico os autorizam a um quase processo de legislar em causa própria. Conforme pesquisas de Iannini (2011), a formação de profissionais na área das tecnologias de informação e de comunicação necessita crescer, no mínimo, 10 vezes para atender à demanda do mercado.

O conjunto de capacidades cognitivas para ler, escrever e fazer operações matemáticas, que foi fundamental para o exercício da cidadania até o século passado, necessita ser ampliado, acrescido da habilidade do pensamento computacional, essa capacidade de descrever, de explicar, de operar com situações complexas. As concepções quanto à alfabetização e ao letramento digital têm sido ampliadas radicalmente. Dos processos de instrumentalização para o uso de recursos computacionais, passa-se à necessidade de desenvolver as habilida- 
des exigidas para atuar na sociedade do século XXI, em especial, utilizar saberes e dispositivos tecnológicos para construir respostas a problemas.

Este artigo problematiza a implementação da Oficina de Pensamento Computacional com estudantes dos anos finais do ensino fundamental e do ensino médio, em uma instituição de educação básica, em Porto Alegre. Discutem-se, inicialmente, as premissas que justificam sua inclusão na grade curricular, delineando as estratégias de implementação, de acompanhamento e de avaliação desta ação pedagógica.

\section{Pensamento computacional versus educação básica}

A complexidade dos problemas contemporâneos aponta para a obrigatoriedade de aprofundar a discussão em torno das possibilidades de superar a adversidade da infraestrutura física e técnica das instituições educacionais, para imprimir qualidade aos processos de ensino e de aprendizagem. Ao assumir como foco investigativo a necessidade de desenvolver o pensamento computacional na educação básica, deve-se observar a transversalidade que caracteriza esse conceito, evidenciada pela forma consorciada com que opera com outras linguagens e, por isso, com outras formas de pensar: a matemática, a científica, a filosófica, a linguística, a tecnológica.
Problematizar a necessidade de inserção da habilidade do pensamento computacional na escola alinha-se com os princípios da "pedagogia da pergunta”, expressão cunhada por Freire (1985) em sua defesa incondicional da aprendizagem centrada no aluno. Essa abordagem pedagógica tem como premissa uma aprendizagem mediada por perguntas a partir das quais é possível investigar e encontrar soluções para problemas, de modo a desenvolver um pensamento ativo, criativo e crítico nos estudantes. Para Freire (1985), o processo de aprendizagem é impulsionado pela ideia central de que todo conhecimento começa pela pergunta e pela curiosidade. A pergunta desperta e conserva a curiosidade e a crítica, e, por meio do processo cognitivo de questionar, qualificam-se o pensar, o imaginar, o criar, conduzindo ao desenvolvimento de diferentes habilidades e competências.

Para destacar a importância do pensamento computacional para o viver contemporâneo, o pesquisador e professor da Universidade de Évora José Ramos (2016) elege a metáfora do "canivete suíço cognitivo", afirmando que essa forma de pensar empodera o indivíduo com uma série de ferramentas, pois, quanto maior forem o número e a especificidade desses recursos intelectuais, maior é o conjunto de problemas a serem enfrentados e solucionados com sucesso. 
De Seymour Papert (1994) a Jeannette Wing (2006), defende-se o pensamento computacional como uma habilidade para todos, não se instituindo como um campo de conhecimento restrito aos cientistas da computação. Como pioneiros na problematização do conceito e no reconhecimento da importância de sua inserção no cenário escolar, esses pesquisadores caracterizam o pensamento computacional pelo princípio da universalidade, justificado pelas dimensões cognitivas envolvidas e pela forma humana de pensar e de resolver problemas, que, por isso, antecede a existência do próprio computador.

O ganho cognitivo da inserção do pensamento computacional na educação básica está em empoderar jovens estudantes na forma de proceder à resolução de problemas, em sua capacidade para descrever e explicar situações complexas. Estudantes investidos do poder de uma ferramenta cognitiva para resolver problemas de forma mais ágil e apoiados na transversalidade das diferentes áreas do conhecimento passam a analisar dados logicamente e a representá-los de forma abstrata; a espacializar as etapas do processo de resolução de problemas; a particionar problemas complexos, resolvendo-os por meio da discussão de variáveis e de estruturas condicionais.

Problematizar a presença do pensamento computacional na educação básica aproxima-se, também, das discussões da afirmação tecida por Carlson (2007), que adverte sobre o perfil dos estudantes que, imersos nas dinâmicas da cibercultura, estudam em instituições que ainda operam para o disciplinamento do corpo e do saber, interpelados pelas configurações espaçotemporais do século XIX e $\mathrm{XX}$, para ilustrar o agrupamento de turma e de ano letivo da grade curricular.

Nem todos os problemas podem ser resolvidos usando o computador. Entretanto, boa parte dos desafios a serem equacionados pode se beneficiar do pensamento computacional, utilizando alguns de seus princípios centrais, como destaca Ramos (2016), dividir e conquistar. Apoiados por esse "canivete suíço cognitivo" do pensamento computacional, podemos operar problemas complexos que se revelam inicialmente de difícil solução, mas que, por meio de sua decomposição em questões menores, projetam os passos que viabilizam sua resolução. Pensamento computacional conduz à construção de uma representação mais apropriada, para tornar o problema tangível. Operar sob a lógica do pensamento computacional impulsiona o desenvolvimento de diversas competências e, em especial, contribui para o estudo de conceitos matemáticos. Entre as competências, destacam-se as elencadas na matriz de referência curricular da instituição educativa participante da pesquisa, evidenciando a relevância da inserção dessa temática na composição 
curricular da educação básica (UNIÃO MARISTA DO BRASIL, 2016).

- Competências acadêmicas: estabelecer conexões entre temas matemáticos de diferentes campos e conhecimentos de outras áreas do saber; desenvolver o espírito investigativo, crítico e criativo no contexto de situações-problemas, produzindo registros próprios e buscando diferentes estratégias de solução.

- Competências ético-estéticas: desenvolver no estudante a segurança de sua própria capacidade de construir conhecimentos em diferentes campos do saber e elevar a autoestima e a perseverança na busca de soluções, trabalhando coletivamente; provocar a análise reflexiva de problemas ao desenvolver habilidades intrapessoais e interpessoais, posicionando-se socialmente de forma crítica, criativa e solidária.

- Competências políticas: selecionar, organizar e produzir informações relevantes, para interpretá-las e avaliá-las criticamente.

- Competências tecnológicas: reconhecer as tecnologias digitais, a fim de compreender e verificar conceitos matemáticos nas práticas sociocientíficas; apropriar-se de tecnologias no campo da matemática, de suas relações com as ciências, reconhecendo sua presença, e de seus impactos na vida, de forma a avaliar o seu uso no âmbito sociocultural.

O exercício do pensamento computacional projeta uma estrutura que conduz a um modelo mental para a resolução de problemas, beneficiando diferentes áreas do conhecimento. Com a Oficina de Pensamento Computacional, instituiu-se um espaço extracurricular para organizar estratégias mais produtivas, a fim de operar com problemas, ao delinear um conjunto de etapas para a sua resolução: 1) reconhecer e analisar dados do problema; 2) dividir o problema complexo em um conjunto de problemas menores; 3) identificar padrões, localizando dados que se repetem; 4) propor abstrações, simplificando as características importantes do problema; 5) criar algoritmos, desenvolvendo uma sequência de pequenas soluções para o problema; 6) construir modelos, simulando, testando, procurando possíveis falhas. A resolução de problemas complexos convida estudantes a resgatar conhecimentos e experiências mobilizados por meio da concretização dessas etapas, forjando o desenvolvimento de habilidades e, consequentemente, de competências. 


\section{Oficina de Pensamento}

\section{Computacional: do consumo à produção tecnológica}

A Oficina de Pensamento Computacional, embora previsse, inicialmente, a oferta de 20 vagas, contou com o entusiasmo dos estudantes em relação à temática e atingiu 71 solicitações de inscrições. Diante dos pedidos de participação por parte dos alunos e de seus familiares, as coordenações pedagógicas do ensino médio e do ensino fundamental (séries finais) concordaram com a abertura de uma segunda turma, totalizando, assim, 40 participantes. Foi curioso, no dia de abertura da oficina, a reunião de 48 estudantes, indicando que oito deles, mesmo não tendo sido contemplados no primeiro ou no segundo sorteio, marcavam presença no desejo de efetivar a matrícula. Entre esses "alunos penetras", destaca-se J. P. R., estudante do $9^{\circ}$ ano, que não faltou a encontro algum e se envolveu ativamente em todos os desafios propostos no desenvolvimento da oficina.
Metodologicamente, a oficina configura-se como uma ação educativa ancorada na aprendizagem baseada em projetos, por: 1) desenhar uma ação pedagógica que se aproximou da identidade dos estudantes, favorecendo a construção de subjetividades; 2) conduzir a ressignificação curricular, dando sentido e contextualização a saberes no âmbito de diferentes áreas do conhecimento, em especial, da matemática e da física; 3) potencializar um diálogo crítico com problemas e fenômenos que acontecem fora do espaço-tempo escolar; 4) tecer momentos de fala e de escuta, para que estudantes possam expressar ideias e concretizar habilidades; 5) problematizar situações do mundo real, conduzindo a uma aprendizagem mais significativa.

A Oficina de Pensamento Computacional foi organizada em três grandes módulos e estruturada em 17 horas-aula, conforme apresentado no Quadro 1. Nesse espaço-tempo para o aprender, os módulos operaram de forma interdependente e complementar. 
Quadro 1 - Estrutura curricular: detalhamento dos módulos e da carga horária

\begin{tabular}{|c|c|c|c|}
\hline Módulo & Campo Conceitual & Estratégias implementadas & Hora-aula \\
\hline 1 & $\begin{array}{l}\text { Apropriação teórica, } \\
\text { Introdução à lógica } \\
\text { de programação, } \\
\text { Introdução ao pen- } \\
\text { samento computa- } \\
\text { cional }\end{array}$ & $\begin{array}{l}\text { Pensamento computacional: percursos histórico e } \\
\text { teórico-prático, pesquisadores, linguagens e tecno- } \\
\text { logias; } \\
\text { Pensamento computacional como uma metodolo- } \\
\text { gia para a resolução de problemas; } \\
\text { Jogos de tabuleiro (Christian Puhlmann Brack- } \\
\text { mann); } \\
\text { Introdução à programação: [code.org e lightbot. } \\
\text { com]; } \\
\text { Programação - Scratch: instrumentalização; Cons- } \\
\text { trução de animações e de jogos. }\end{array}$ & 5 \\
\hline \multicolumn{4}{|c|}{ Entrega parcial do Módulo 1 - jogos e animações + autoavaliação } \\
\hline 2 & $\begin{array}{l}\text { Conceitos de eletrô- } \\
\text { nica, } \\
\text { Funcionalidades da } \\
\text { Placa Arduino e da } \\
\text { interface S4A }\end{array}$ & $\begin{array}{l}\text { Componentes eletrônicos do Arduino (protoboard, sen- } \\
\text { sores, componentes eletrônicos básicos e motores); } \\
\text { Exploração das funcionalidades da interface S4A } \\
\text { (similar ao Scratch); } \\
\text { Exploração e aplicação dos comandos do Arduino; } \\
\text { Exercícios de raciocínio lógico com leds e botões. }\end{array}$ & 5 \\
\hline \multicolumn{4}{|c|}{ Entrega parcial do Módulo 2 - resolução dos exercícios + autoavaliação } \\
\hline 3 & $\begin{array}{l}\text { Gerenciamento de } \\
\text { projeto, } \\
\text { Prototipação do pro- } \\
\text { duto final }\end{array}$ & $\begin{array}{l}\text { Instrumentalização para a utilização da impressora } \\
\text { 3D; } \\
\text { Resolução de problemas reais e representação di- } \\
\text { gital; } \\
\text { Formação das equipes de trabalho; } \\
\text { Identificação do problema, proposição das etapas } \\
\text { de resolução, definição do plano de resolução (deli- } \\
\text { mitação de tarefas e das entregas parciais e finais); } \\
\text { Apresentação dos produtos finais (maquetes): pro- } \\
\text { blemas, plano de resolução do problema, prototi- } \\
\text { pação; } \\
\text { Mostra da Oficina de Pensamento Computacional; } \\
\text { Certificação. }\end{array}$ & 7 \\
\hline
\end{tabular}

Fonte: elaboração dos autores.

O Módulo 1 foi estruturado para aproximar os estudantes dos conceitos centrais do pensamento computacional, contextualizando o processo histórico da emergência do termo e das investigações que conduziram à construção desse campo de conhecimento. Um polígrafo foi elaborado como material de apoio (Figura 1); também foi organizado um espaço virtual no Moodle, para facilitar o acesso aos materiais e otimizar a comunicação e a interação entre estudantes e educadores. 
Figura 1 - Polígrafo Módulo 1

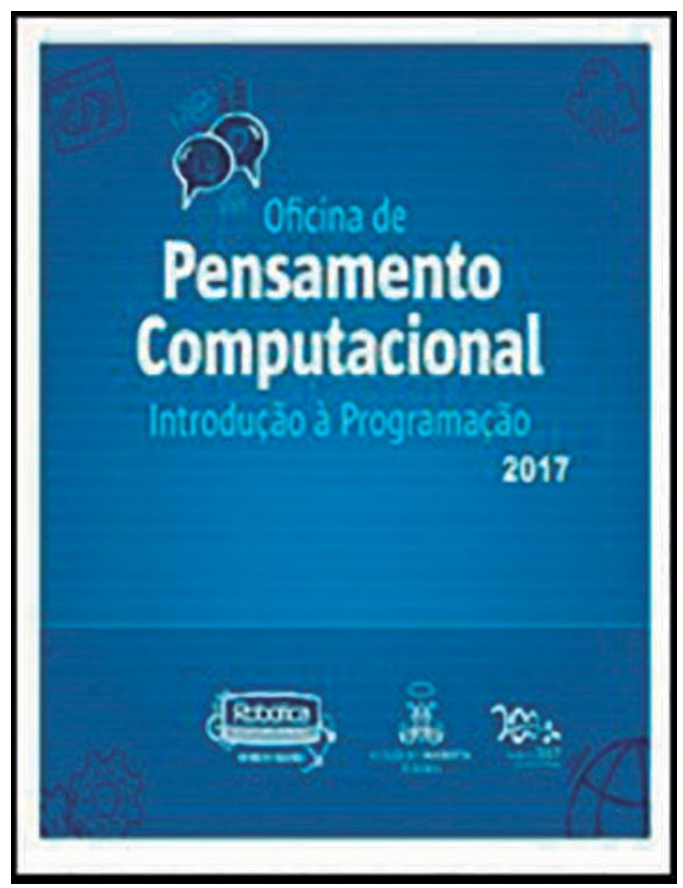

Fonte: elaboração dos autores.

Esse módulo objetivou forjar no estudante a percepção do pensamento computacional como uma metodologia para resolução de problemas, como instrumento operacional para elevar o seu poder cognitivo, possibilitando a ele enxergar as situações de diversas perspectivas. Para a concretização desse objetivo, os estudantes interagiram com jogos elaborados e validados por Christian Puhlmann Brackmann (2017) em sua investigação de doutorado e trabalharam com imagens de situações cotidianas para exercitar o "particionamento" do desafio, o desdobramento da ação, o reconhecimento e a associação de problemas mais simples, para, assim, otimizar sua resolução (Figuras 2 e 3).

Figura 2 - Jogos lógicos propostos por Brackmann
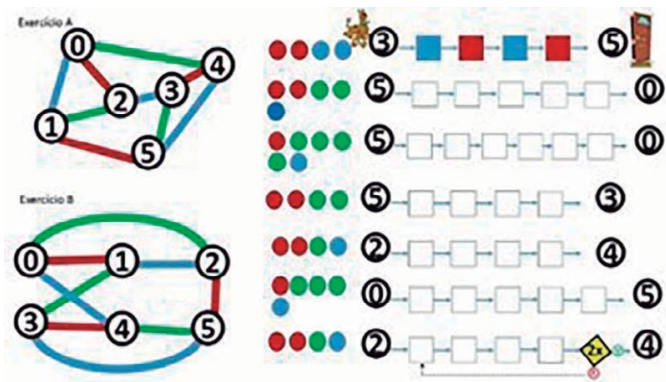

Fonte: Brackmann (2017).

Figura 3 - "Particionamento" de problemas Lavar as mãos
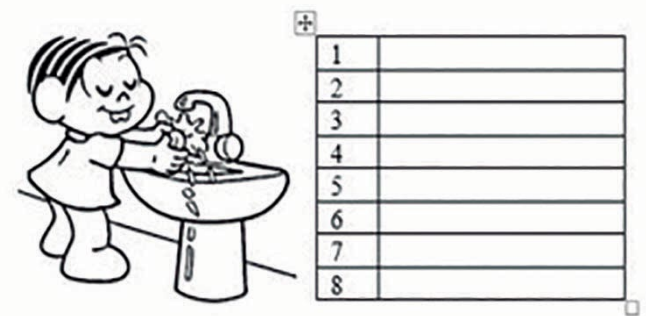

Fonte: elaboração dos autores.

As investigações de Ada Lovelace e de Joseph Marie Jacquard (HISTÓRIA DA..., 2011) para problematizar as origens do pensamento computacional como estratégia de resolução de problemas complexos foram discutidas no Módulo 1. Os recursos de programação do projeto norte-americano Code.org foram utilizados para abordar outras alternativas de aprendizagem de programação, dando início à fase "plugada" da oficina. 
O Módulo 1 foi finalizado com a introdução ao Scratch, linguagem gráfica de programação inspirada nos blocos de Lego. Foi instigante constatar que os estudantes não demoraram a perceber que por meio dos recursos do Scratch conquistavam uma nova caixa de ferramentas para inventar soluções para os problemas e desafios propostos.

Os jovens aprendizes, ao operarem com base nos princípios do pensamento computacional, mostraram-se absolutamente envolvidos e comprometidos com o próprio processo de aprendizado. Foi surpreendente constatar a motivação e a velocidade com que os estudantes realizavam as tarefas, chegando a confidenciar que a expectativa inicial em relação à oficina havia sido superada.

O resultado positivo do Módulo $1 \mathrm{im}$ pulsionou a organização de duas equipes: Shuma, composta por estudantes do $9^{\circ}$ ano do ensino fundamental, e Sad Boys, composta por alunos do $1^{\circ}$ ano do ensino médio, para participação no Festival Marista de Robótica, na modalidade Incubando Ideias. Para o fechamento do Módulo 1, foi solicitado aos participantes que realizassem uma avaliação dessa etapa da Oficina de Pensamento Computacional. O link de acesso ao formulário on-line foi publicado no Moodle organizado para a oficina; e o questionário estava estruturado da seguinte forma: a primeira parte apresentava questões objetivas para analisar a adequação do tempo, revelando $96,4 \%$ de satisfação, e o grau de atendimento às expectativas de aprendizagem, apontando $89,3 \%$ de satisfação; e a segunda parte envolveu questões abertas, para que os estudantes registrassem seu entendimento sobre pensamento computacional. Algumas das respostas obtidas foram as seguintes: "Entendo que é um pensamento prático e objetivo, onde é possível chegar em uma resposta através de caminhos divergentes" (Aluno 8); "Forma de automatizar problemas do cotidiano em busca da maior eficiência possível" (Aluno 12); "Em minha compreensão, pensamento computacional caracteriza como o pensamento ordenado, funcional e com propósito direcionado" (Aluno 18).

No Módulo 2, os participantes interagiram com o Arduino, uma plataforma de prototipagem para que os estudantes explorassem os recursos e as funcionalidades da protoboard, uma placa com matriz e contatos que permite a construção de circuitos experimentais sem a necessidade de solda (Figura 4). Essa facilidade imprimiu ao projeto de prototipação maiores rapidez e segurança para a alteração da posição de componentes ou para a substituição. Os estudantes exploraram a utilização de componentes eletrônicos da Protoboard Arduino (sensores, capacitores, diodos, resistores, transistores, circuitos integrados, motores) e as funcionalidades da interface Scratch for Arduino (S4A) para 
a programação. O produto final do Módulo 2 foi a resolução de desafios lógicos com leds e botões (Figura 5).

Figura 4 - Orientações para a montagem de circuitos

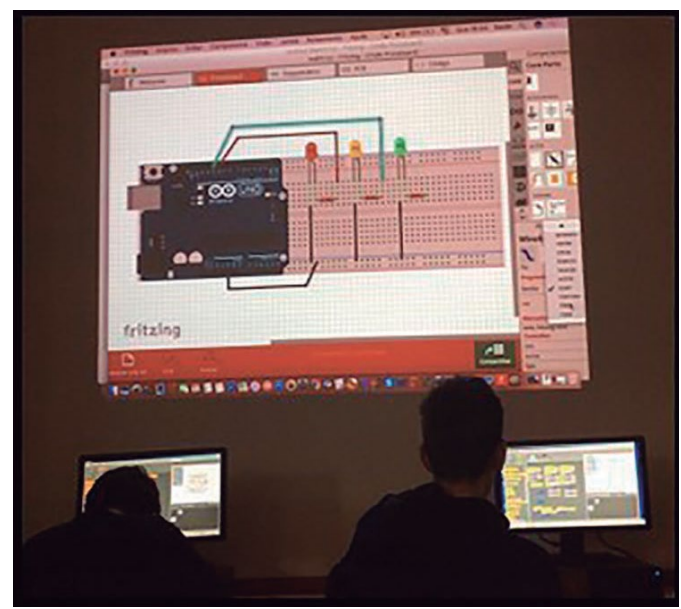

Fonte: elaboração dos autores.

Figura 5 - Estudante gerenciando sensores conectados ao Arduino

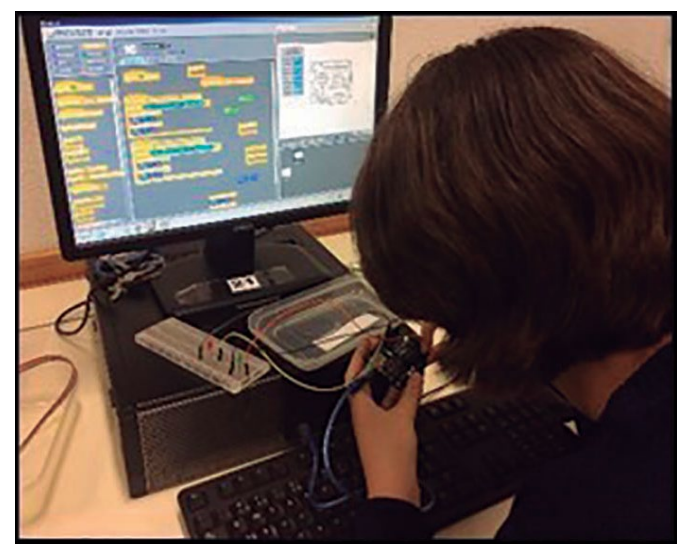

Fonte: elaboração do autores.

Desenvolver habilidades para trabalhar em equipe foi o fio condutor do Módulo 3 , por ser a etapa da oficina na qual os estudantes realizaram a análise de contexto para a proposição do problema e a projeção do ordenamento das etapas e das estratégias de gerenciamento da solução por meio de sua prototipação.

Nesse módulo, os estudantes aplicaram os conhecimentos aprendidos nas etapas anteriores para a construção do protótipo, processo que culminou na apresentação do produto final de cada equipe para pais e convidados (Figura 6).

Figura 6 - Participação dos pais: valorização do espaço-tempo e da parceria entre gerações

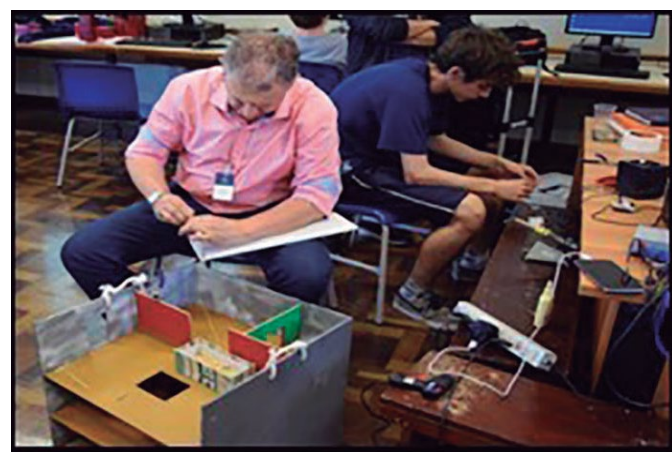

Fonte: elaboração dos autores.

\section{Oficina de Pensamento Computacional: a voz dos estudantes}

Metodologias ativas valorizam a participação efetiva dos alunos na construção do conhecimento e no desenvolvimento de competências. Por meio da mediação de docentes inspiradores, ao mesmo tempo em que impulsionaram 
a incorporação de outras estratégias de resolução de problemas complexos por dispositivos pelo mundo digital, jovens aprendizes vivenciaram um contexto pedagógico que amplia o desenvolvimento das competências exigidas no século XXI. A fundação norte-americana National Research Council (2012) consultou especialistas de diferentes áreas, para mapear essas competências. Como resultado, esse conjunto de competências foi organizado em três grandes domínios, que, por sua interdisciplinaridade e complementaridade, possibilitariam a aplicação de conhecimentos.
Vividos 18 anos do século XXI, as agendas educacionais ainda registram questionamentos como: qual conjunto de competência deve compor, ao final de cada ciclo escolar, o perfil de crianças e de jovens para o exercício da cidadania no século XXI? O Quadro 2 apresenta os domínios de competência projetados para a Oficina de Pensamento Computacional, relacionando-os com os dados da avaliação qualitativa registrados e categorizados por meio da Análise Textual de Conteúdo (MORAES, 2003).

Quadro 2 - Domínios de competência

\begin{tabular}{|c|c|}
\hline Domínios de Competência & $\begin{array}{l}\text { Categorização dos dados (Análise Textual de Conteúdo) } \\
\text { Palavra do participante (garantir escuta e voz do estudante) }\end{array}$ \\
\hline $\begin{array}{l}\text { Cognitivo } \\
\text { Estratégias e processo de } \\
\text { aprendizagem: pensamentos } \\
\text { lógico e crítico, memória, cria- } \\
\text { tividade. }\end{array}$ & $\begin{array}{l}\text { "Para mexer no motor, precisávamos usar os ângulos, unidades de } \\
\text { medida para medir a caixa, a conversão de milímetros para centí- } \\
\text { metros, para a modelagem de peças na impressora 3D. Definir o } \\
\text { melhor metal para conduzir energia e a voltagem certa, conversão } \\
\text { de pesos e calcular a movimentação do elevador" (H. G., } 9^{\circ} \text { ano do } \\
\text { ensino fundamental). } \\
\text { "[...] ser utilizado para escrever uma redação, o passo a passo, } \\
\text { da introdução até a conclusão, como nas funções quadráticas de } \\
\text { matemática" (P. B., } 9^{\circ} \text { ano do ensino fundamental). }\end{array}$ \\
\hline $\begin{array}{l}\text { Interpessoal } \\
\text { Capacidade de lidar com } \\
\text { emoções e moldar comporta- } \\
\text { mento para atingir objetivos. }\end{array}$ & $\begin{array}{l}\text { "A oficina me ajudou no trabalho em grupo. Consigo trabalhar me- } \\
\text { lhor o planejamento, a pesquisa e a elaboração de projetos" (L. M., } \\
9^{\circ} \text { ano do ensino fundamental). }\end{array}$ \\
\hline $\begin{array}{l}\text { Intrapessoal } \\
\text { Desenvolver consciência crí- } \\
\text { tica para a auto-organização. }\end{array}$ & $\begin{array}{l}\text { "O pensamento computacional também me ajudou na rotina dos } \\
\text { estudos, já que eu consegui organizar uma sessão de estudos } \\
\text { passo a passo, observando a situação de maneira ampla" (L. M., } \\
9^{\circ} \text { ano do ensino fundamental). }\end{array}$ \\
\hline
\end{tabular}

Fonte: adaptado de Moraes (2003) 


\section{Conclusões}

Os primeiros movimentos desenhados com a chegada do computador na escola foram conduzidos com foco na instrumentalização, para a alfabetização e a conquista da fluência digital. Contemporaneamente, o desenvolvimento humano exige ir além da técnica. Em sintonia com o mesmo movimento vivenciado pela internet, a Web 1.0, o grande repositório linear de informação, se deslocou para a Web 2.0, inaugurando a Era do Usuário e da Geração Interativa, produzida sob a lógica do conceito da inteligência coletiva e explicitada pelas múltiplas possibilidades de partilha e cooperação. O campo de atuação das tecnologias computacionais na escola deve explicitar esse mesmo movimento, a fim de oportunizar que dispositivos digitais potencializem espaços-tempos efetivos de aprendizagem enriquecedora.

Para que a escola seja interpelada pelas possibilidades cognitivas associadas ao pensamento computacional, é preciso criar espaços para que estudantes possam vivenciar experiências interessantes na resolução de problemas. É necessário que o processo educativo possa valorizar e ressignificar muitas ações que já são feitas na escola, para desafiar o estudante a lidar com problemas complexos, a fim de que possa evidenciar persistência, confiança, tolerância ao erro, comunicabilidade e postura cooperativa.

\section{Computational thinking in basic education: tecnological interface in the construction of the twenty-first century competences}

\section{Abstract}

This article discusses the implementation of the Computational Thinking Workshop in the context of Basic Education, in Porto Alegre, aiming to socialize one of the possible answers to the challenge of aligning the school with the demands placed by a sociocultural, political and economic context built by information technologies and Communication. Initially, the premises that justify its inclusion in the curricular grid are outlined, outlining strategies for implementation, monitoring and evaluation of pedagogical action, especially by listening and giving voice to its participants.

Keywords: Basic education. Computational thinking. Technology.

\section{Referências}

BRACKMANN, C. P. Desenvolvimento do pensamento computacional através de atividades desplugadas na educação básica. Tese (Doutorado) - Programa de Pós-Graduação em Informática na Educação, Centro de Estudos Interdisciplinares em Novas Tecnologias na Educação, Universidade Federal do Rio Grande do Sul, Porto Alegre, 2017.

CARLSON, S. The Net Generation in the Classroom. The Chronicle of Higher Education. 2007. Disponível em: <http://chronicle.com/free/v52/ i07/07a033401.htm>. Acesso em: 20 jan. 2018.

ECO, Umberto. O nome da rosa. Rio de Janeiro: Nova Franteira, 1983. 
FREIRE, P. Por uma pedagogia da pergunta. Rio e Janeiro: Paz e Terra, 1985. (Coleção Educação e Comunicação: v. 15).

HISTÓRIA DA COMPUTAÇÃO PARTE 3. 11 dez. 2011. Disponível em: <http://museuvirtualutfpr.blogspot.com/2011/12/em-1801-o-mecanico-frances-joseph-marie.html $>$. Acesso em: out. 2017.

IANNINI, T. O. O perfil dos profissionais de tecnologia da informação. Belo Horizonte: Clube de Autores, 2011.

LÉVY, P. As tecnologias da inteligência: o futuro do pensamento na era da informática. Trad. Carlos Irineu da Costa. Rio de Janeiro: Editora 34, 1993.

MORAES, R. Uma tempestade de luz: a compreensão possibilitada pela análise textual discursiva. Ciência \& Educação, Bauru, v. 9, n. 2, p. 191-211, 2003.

NATIONAL RESEARCH COUNCIL. Education for life and work: developing transferable knowledge and skills in the 21st century. Washington, DC: The National Academies Press, 2012. Disponível em: <https://doi. org/10.17226/13398>. Acesso em: 20 jan. 2018.

PAPERT, S. A máquina das crianças: repensando a escola na era da informática. Trad. Sandra Costa. Porto Alegre: Artes Médicas, 1994.

RAMOS, J. L. Desafios da introdução ao pensamento computacional e à programação no $1^{\circ}$ ciclo do Ensino Básico: racionalizar, valorizar e atualizar. 2016. Disponível em: <http://hdl. handle.net/10174/20223>. Acesso em: 20 jan. 2018. (Conselho Nacional de Educação).

UNIÃO MARISTA DO BRASIL (Brasília) (Org.). Matrizes curriculares da educação básica do Brasil Marista: área de matemática e suas tecnologias. Curitiba: PUCPR, 2016.

WING, J. Computacional Thinking. In: COMMUNICATIONS OF THE ACM. 49., New York, 2006. Anais..., New York, 2006. p. 33-35. 